\title{
IMPLEMENTASI METODE WEIGHTED PRODUCT (WP) DALAM SISTEM PENGAMBILAN KEPUTUSAN DOSEN TERBAIK TEKNIK KOMPUTER AKADEMI ILMU KOMPUTER TERNATE \\ ${ }^{1}$ Ilham Djufri, ${ }^{2}$ Muksin Hi. Abdullah, ${ }^{3}$ Seh Turuy \\ ${ }_{1,2,3}$ Akademi Ilmu Komputer Ternate, Indonesia \\ 1ilham.djufri@aikomternate.ac.id, ${ }^{2}$ muksinabdullah18@gmail.com, ${ }^{3}$ sehturuy85@gmail.com
}

\begin{tabular}{l} 
Article Info \\
\hline Article history: \\
Received, 27/11/2020 \\
Revised, 28/11/2020 \\
Accepted, 1/12/2020 \\
\hline Kata Kunci: \\
SPK, \\
WP, \\
pemilihan, \\
dosen, \\
terbaik
\end{tabular}

Keywords:

DSS,

WP,

election,

lecturer,

best

\begin{abstract}
ABSTRAK
Dosen merupakan tenaga akademik yang bertugas merencanakan dan melaksanakan proses pembelajaran, menilai hasil pembelajaran, melakukan pembimbingan dan pelatihan, serta melakukan penelitian dan pengabdian pada masyarakat (Tri Dharma) Perguruan Tinggi. Dalam melaksanankan Tri Dharma Perguruan Tinggi doesen perlu diberikan apresiasi atau promosi sesuai dengan kinerja akademiknya. Oleh karena itu, peneliti mendesain analisis pengambilan keputusan pemilihan dosen terbaik pada Program Studi Teknik Komputer Akadedemi Ilmu Komputer Ternate. Tujuannya adalah memilih dosen terbaik dengan cara perangkingan. Untuk menentukan dosen terbaik peneliti menggunakan teknik pengambilan data dengan cara penyebaran kuisioner terhadap 16 (enam belas) mahsaiswa Teknik Komputer sebagai penilai terhadap 5 (lima) alternative (dosen) Teknik Komputer dengan menerapkan metode analisis perhitungan metode Weighted Product. Kriteria pemilihan yang digunakan adalah Kemampuan Logika Berpikir, Terampil Melakukan Evaluasi Assessment, Terampil Menyajikan Materi Kuliah dan Kedisiplinan. Data hasil analisis perhitungan mendapatkan Alternatif (dosen) yang memperoleh nilai tertinggi adalah alternative (dosen) ABUR (A4) 0.2328 .
\end{abstract}

\section{ABSTRACT}

Lecturers are academic staff in charge of planning and implementing the learning process, assessing learning outcomes, conducting guidance and training, and conducting research and community service (Three Dharma) for Higher Education. In implementing the Three Dharma of Higher Education, it is necessary to give appreciation or promotion according to its academic performance. Therefore, the researchers designed a decision-making analysis for choosing the best lecturers in the Computer Engineering Study Program, Akademi Ilmu Komputer, Ternate. The goal was to select the best lecturers by ranking. To determine the best lecturer, the researchers used data collection techniques by distributing questionnaires to 16 (sixteen) Computer Engineering students as assessors of 5 (five) alternative (lecturers) Computer Engineering by applying the calculation analysis method of the Weighted Product method. The selection criteria used are Logic Thinking, Synthesis Analysis Ability, Material Delivery Methods and Dress Procedures (Appearance). The data from the calculation analysis indicated that the alternative (lecturer) who got the highest score was the alternative (lecturer) ABUR (A4) 0.2328.

This is an open access article under the CC BY-SAlicense.

\section{PENDAHULUAN}

Penyelenggaraan pendidikan di Perguruan Tinggi tidak lepas dari peran dosen. Dosen merupakan tenaga akademik yang berfungsi sebagai merencanakan dan melaksanakan kegiatan pembelajaran, penelitian dan pengabdian kepada masyarakat (Sujaini, Herry, and Helen Sasty Pratiwi. 2016) [1]. Dosen adalah orang yang berpengalaman dalam bidang profesi. Dengan keilmuan yang dimilikinya dapat menjadikan anak didik menjadi orang yang cerdas (Rini, Dedi, and Riyanti 2015) [2]. 
Pemilihan dosen terbaik secara periodik dapat memacu semangat dosen dalam meningkatkan dedikasi dan kinerja. Namun pada Program studi Teknik Komputer Akademi Ilmu Komputer Ternate belum pernah dilaksanakan pemilihan atau penilaian dosen terbaik, hal ini disebabkan oleh belum tersedianya media dan Standar Operasional Prosudur (SOP) sebagai pedoman atau acuan untuk melaksakan tugas pekerjaan sesuai dengan fungsi dosen Program Studi Teknik Komputer pada Akademi Ilmu Komputer Ternate berdasarkan indicator-indikator teknis, administrative dan prosudural sesuai dengan tata kerja proses belajar mengajar yang dapat memproses penilaian dosen dan memberi perankingan dalam pemilihan dosen terbaik (Widagdo et al. 2019) [3].

Untuk pemilihan dosen terbaik Program Studi Teknik Komputer pada Akademi Ilmu Komputer Ternate membutuhkan system, dalam hal ini peneliti menggunakan system pendukung keputusan dengan metode Weighted Product (WP ) yang dapat mengolah setiap data dalam model algoritma agar dapat menghasilakan nilai keputusan sebagai Alternatif (dosen) terbaik. Hal ini dapat menjadi nilai tambah bagi Akademi Ilmu Komputer Ternate yang belum memiliki manajemen sistem secara menyeluruh sehingga dapat mendukung nilai akreditasi kampus dengan memanfaatkan hasil penelitian ini untuk membangun system Informasi dengan merancangan aplikasi system pengambilan keputusan.

Penelitian yang dilaksakan oleh (Sulastri, C., Siswanti, S., \& KW) [4] dengan judul "SPK Penilaian Dosen Berprestasi Menggunakan metode Weighted Product (WP) Di STIKKES ALMA ATA Yogyakarta”. Tujuan untuk menyajikan informasi dengan mengimplementasikan metode Weighted Product untuk mempermudah dalam menentukan penilaian dosen berprestasi. Penelitian terkait lainnya yang dilakukan oleh (Marpaung, Handayani, and Yesputra 2018) [5] dengan judul "SPK Pemilihan Dosen Terbaik Dengan Metode Weighted Product (WP) Pada STMK RORAL" Penelitian ini untuk memberikan kemudahan bagi pengambil keputusan untuk memilih dosen terbaik di kampus STMK RORAL.

Tinjauan penelitian yang dilakukan oleh (Hidayat, Mufizar, and Ramdani) [6] dengan judul "Implementasi Metode Weighted Product. Pada SPK Seleksi Calon Karyawan BPJS Kesehatan Tasikmalaya". Menerapkan sistem pendukung keputusan seleksi calon karyawan dengan Metode Weighted Product. Sedangkan penelitian yang dilakukan oleh peneliiti bertujuan untuk menerapkan metode perhitungan metode Weigthed Product untuk pemilihan dosen terbaik pada Program Studi Teknik Komputer pada Akadedemi Ilmu Komputer (AIKOM) Ternate, dengan teknik pengambilan data penyebaran kuisioner dan hasil perhitungannya dilengkapi dengan grafik yang tidak diliki oleh penelitian sebelumnya, sehingga mempermudah untuk pembacaan hasil pemilihan dosen terbaik.Konsep Sistem Pendukung Keputusan (SPK) atau Decision Support Systems (DSS) pertama kali diungkapkan pada awal tahun 1970-an oleh Michael S. Scott Morton dengan istilah Management Decision System [7].

Sistem Pendukung Keputusan/Decision Support System (DSS) merupakan sisten informasi interaktif yang menyediakan informasi, pemodelan, dan pemenipulasian data. Sistem itu digunakan untuk membantu pengambilan keputusan dalam situasi yang semi-terstruktur, dimana tak seorang pun tahu secara pasti.DSS tidak dimaksudkan untuk mengotomisasi pengambilan keputusan, tetapi memberikan perangkat interaktif yang memungkinkan pengambilan keputusan untuk melakukuakn berbagai analisis menggunakan model-model yang tersedia [8].

Tujuan dari Sistem Pengambilan keputusan adalah untuk membantu pengambilan keputusan memilih berbagai alternative keputusan yang merupakan pengolahan informasi-informasi yang diperoleh atau tersedia dengan menggunakan model mengambilan kepiutusan. Ciri utama sekaligus keunggulan dari system pendukung keputusan tersebut adalah kemampuannya untuk menyelesaikan masaalah-masaalah yang tidak terstruktur [9]. Metode Weighted Product (WP) adalah sebuah metode dari Multiple Attribute Decision Making (MADM). MADM adalah suatu metode yang digunakan untuk mencari alternatif optimal dari sejumlah alternatif dengan kriteria tertentu. Inti dari MADM adalah menentukan nilai bobot untuk setiap atribut, kemudian dilanjutkan dengan proses perankingan yang akan menyeleksi alternatif yang sudah diberikan [10]. Metode Weighted Product merupakan perkalian untuk menghubungkan rating atribut ,dimana rating dari setiap atribut harus dipangkatkan dengan bobot atribut yang bersangkutan. Metode Weighted Product memerlukan proses normalisasi karena metode ini mengakalikan setiap atribut. Hasil perkalian tersebut belum bermakna jika belum dibandingkan dengan nilai standar. Bobot untuk atribut berfungsi sebagai pangkat 
JSAI : Journal Scientific and Applied Informatics

Vol. 3, No. 3, November 2020, hal. 175 182

E-ISSN: 2614-3054; P-ISSN: 2614-3062, accredited by Kemenristekdikti, Sinta 5

DOI: 10.36085

positif dalam proses perkalian, sementara bobot biaya berfungsu sebagai pangkat negative. Proses pengambilan keputusan [11] yang dapat dilakukan oleh pembuat keputusan menggunakan Sistem Pengambilan Keputusan. Awalnya, pengambil keputusan memilih lokasi pusat yang akan diteliti. Kemudian, pembuat keputusan memilih alternative dan kriteria yang akan digunakan dalam penelitian.

Sistem manajemen database atau database management system (DBMS) adalah merupakan suatu sistem software yang memungkinkan seorang user dapat mendefinisikan, membuat, dan memelihara serta menyediakan akses terkontrol terhadap data. Database sendiri adalah sekumpulan data yang berhubungan dengan secara logika dan memiliki beberapa arti yang saling berpautan [12]. $M A D M$ adalah [13] suatu metode yang digunakan untuk mencari alternatif optimal dari sejumlah alternatif dengan kriteria tertentu. Inti dari MADM adalah menentukan nilai bobot untuk setiap atribut, kemudian dilanjutkan dengan proses perankingan yang akan menyeleksi alternatif yang sudah diberikan. Ada beberapa metode yang dapat digunakan untuk menyelesaikan masalah MADM antara lain.
a. Simple Additive Weighting Method (SAW)
b. Weighted Product (WP)
c. Technique for Order Preference by
d. Similarity to Ideal Solution (TOPSIS)
e. Analytic Hierarchy Process (AHP)

\section{METODE PENELITIAN}

\subsection{Kerangka Penelitian}

Metode penelitian yang digunakan adalah metode kualitatif, Teknik dan jenis pengumpulan data yang digunakan untuk memperoleh data sebagai bahan perhitungan algoritma dalam penelitian ini adalah menggunakan metode Weihted Product. Penulis menggunakan teknik pengumpulan data berupa sumber data primer dengan teknik penyebaran kuisioner [14]. Dengan jumlah sebaran 16 (enam belas) kuisioner yang di nilai oleh Mahasiswa program studi Teknik Komputer dengan 5 (lima) alternative (dosen) Program Studi Teknik Komputer. Alur penelitian dengan metode Weighted Product sebagai berikut;

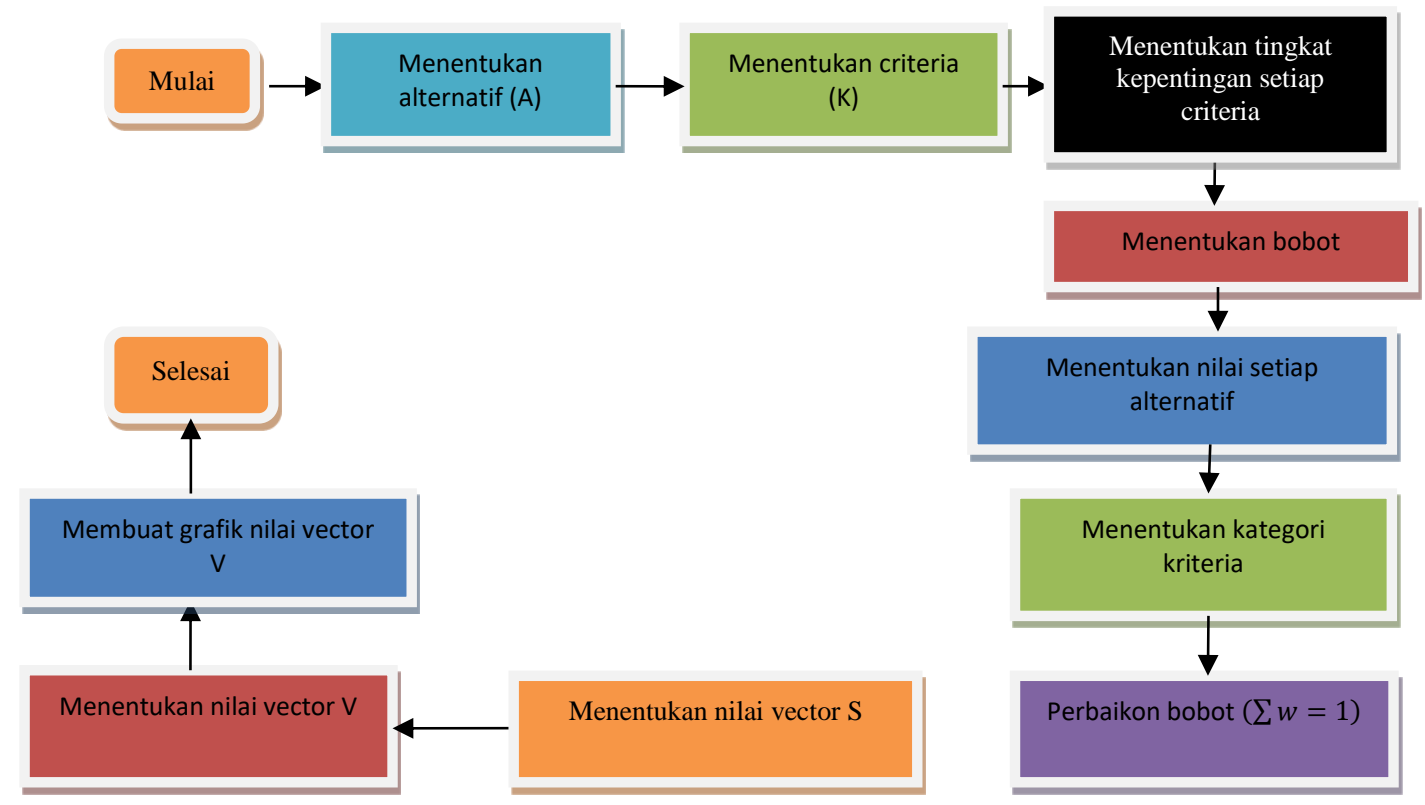

Gambar 1. Alur Penelitian 
JSAI : Journal Scientific and Applied Informatics

Vol. 3, No. 3, November 2020, hal. 175 182

E-ISSN: 2614-3054; P-ISSN: 2614-3062, accredited by Kemenristekdikti, Sinta 5

DOI: 10.36085

\subsection{Langkah-langkah analisis perhitingan.}

Menentukan Alternatif (A) [15].

a. Pada penelitian ini penentuan alternative menggunakan 5 (lima) Alternatif (dosen) sebagai obyek yang akan dinilai oleh 16 (enm belas) mahsiswa Teknik Komputer dengan metode pengisian kuisioner.

b. Menentukan Kriteria (K).

Kriteria penilaian (pemilihan) yang digunakan adalah Kemampuan Logika Berpikir, Terampil Melakukan Evaluasi Assessment, Terampil Menyajikan Materi Kuliah dan Kedisiplinan.

c. Menentukan tingkat kepentingan suatu criteria.

Tingkat kepentingan kriteria yang digunakan adalah Sangat Penting, Penting, Kurang Penting dan Tidak Penting.

d. Menentukan bobot kriteria.

Dengan bobot kriteria Sangat penting $=6$, Penting $=5$, Kurang Penting $=4$ dan tidak Penting $=2$

e. Menentukan nilai setiap alternative disetiap criteria.

Nilai Alternatif dari setiap Kriteria yang yang digunakan adalah Logika berpikir $=6$, Kemampuan analisa sintesis $=5$, Metode penyampaian materi kulaiah $=4$ dan Cara Berpakaian (Penampilan) $=2$

f. Menentukan kategori disetiap criteria. Berpangkat negative bila termasuk kategori minimal, dan berpangkat positif bila termasuk kategori maksimal. Untuk Kriteria Kemampuan Logika Berpikir, Terampil Melakukan Evaluasi Assessment, Terampil dan Menyajikan Materi Kuliah adalah kategori Maksimal dan Kedisiplinan adalah kategori Minimal.

g. Melakukan perbaikan/normalisasi bobot $\left(\sum w=1\right)$.

h. Untuk melakukan normalisasi bobot criteria menggunakan persamaan;

$$
\mathbf{W}_{\mathrm{j}}=\frac{W j}{\sum_{j=1}^{n} W j}
$$

i. Menghitung nilai Vektor S.

Menentukan Nilai Vektor (S) dapat menggunakan persamaan sebagai berikut;

$$
\mathbf{S i}=\prod_{j=1}^{n} X \boldsymbol{i} j \boldsymbol{W J}
$$

j. Menghitung nilai Vektor $V$ yang akan digunakan perankingan. Nilai Vi yang terbesar mengindikasikan bahwa Ai adalah yang lebih dipilih.

k. Menentukan Nilai vector $V$. Dengan menggunakan persamaan berikut ini untuk menghitung preferensi untuk perangkingan;

$$
\mathrm{Vi}=\frac{S i}{\prod_{j}^{n}\left(X_{j}^{*}\right) W j}
$$

1. Hasil perhitungan nilai vector $\vee$ dibuatkan dalam grafik.

\section{Hasil dan Pembahasan}

A. Hasil

\section{Pengolahan data Weight Product}

Teknik pengambilan data anlisis perhitungan metode Weight Product yang digunakan adalah penyebaran kuisioner yang menjadi obyek penyebaran adalah mahasiswa Teknik Komputer terdiri dari 16 (enam belas) kuisioner terhadap 5 (lima) dosen Teknik Komputer sebagai Alternatif. Rating kecocokan adalah 1. Sangat Penting, 2. Penting, Cukup Penting, 4. Kurang Penting.

Pengambilan keputusan memberikan bobot referensi Kriteria $W=(6,5,4.2)$

Normalisasi bobot Persamaan dengan menggunakan persamaan sebagai berikut;

$$
\mathbf{W}_{\mathbf{j}}=\frac{W j}{\sum_{j=1}^{n} W j}
$$


JSAI : Journal Scientific and Applied Informatics

Vol. 3, No. 3, November 2020, hal. 175 182

E-ISSN: 2614-3054; P-ISSN: 2614-3062, accredited by Kemenristekdikti, Sinta 5

Tabel 1. Alternative Kriteria

\begin{tabular}{clc}
\hline Kritria & \multicolumn{1}{c}{ Keterangan } & Bobot \\
\hline K1 & Kemampuan Logika Berpikir & 6 \\
K2 & $\begin{array}{l}\text { Terampil Melakukan Evaluasi } \\
\text { Assessment }\end{array}$ & 5 \\
K3 & $\begin{array}{l}\text { Terampil Menyajikan Materi } \\
\text { Kuliah } \\
\text { K4 }\end{array}$ & 4 \\
\hline
\end{tabular}

B. Pengambilan keputusan memberikan bobot referensi $\operatorname{Kriteria} W=(6,5,4.2)$.

\section{Normalisasi bobot Kriteria}

Normalisasi adalah proses penskalaan nilai atribut dalam rentang tertentu (seperti 0 hingga 1), dengan cara yang semua perilaku memiliki besaran yang kira-kira sama.

a. Normalisasi bobot criteria menggunakan persamaan (1) dapat dilihat dari $\mathrm{W}_{1}, \mathrm{~W}_{2}$, $\mathrm{W}_{3}$, dan $\mathrm{W}_{4}$.

$$
\begin{aligned}
& W_{1}=\frac{6}{6+5+4+2}=\frac{6}{17}=\mathbf{0 . 3 5 2 9} \\
& \mathbf{W}_{\mathbf{2}}=\frac{\mathbf{5}}{6+5+4+2}=\frac{\mathbf{5}}{17}=\mathbf{0 . 2 9 4 1} \\
& \mathbf{W}_{\mathbf{3}}=\frac{4}{6+5+4+2}=\frac{4}{17}=\mathbf{0 . 2 3 5 2 3} \\
& \mathbf{W}_{\mathbf{4}}=\frac{\mathbf{2}}{6+5+4+2}=\frac{2}{17}=\mathbf{0 . 1 1 7 6}
\end{aligned}
$$

b. Selanjutnya adalah hasil normalisasi pembobotan Kriteria yang dapat dilihat pada tabel berikut;

Tabel 2. Hasil normalisasi bobot criteria

\begin{tabular}{cc}
\hline Kriteria & Hasil normalisasi \\
\hline K1 & 0.3529 \\
K2 & 0.2941 \\
K3 & 0.2353 \\
K4 & 0.1176 \\
\hline
\end{tabular}

\begin{tabular}{|c|c|c|c|c|c|}
\hline \multirow{2}{*}{$\begin{array}{l}\text { NAMA DOSEN/ } \\
\text { ALTERNATIF }\end{array}$} & \multirow[t]{2}{*}{ CODE } & \multicolumn{4}{|c|}{ KRITERIA/BOBOT } \\
\hline & & K1 & K2 & K3 & K4 \\
\hline DSMU & A1 & 0.2656 & 0.2469 & 0.1938 & 0.2938 \\
\hline INTS & A2 & 0.2531 & 0.2219 & 0.2969 & 0.2281 \\
\hline TNSA & A3 & 0.2188 & 0.2219 & 0.1938 & 0.3656 \\
\hline ABUR & A4 & 0.2750 & 0.2563 & 0.2719 & 0.1969 \\
\hline USTH & A5 & 0.2595 & 0.2438 & 0.2938 & 0.2031 \\
\hline
\end{tabular}

Nilai hasil pemilihan data dosen terbaik Program Studi Teknik Komputer berdasarkan kuisioner.

Tabel 3. Penilaian Mahasiswa Teknik Komputer terhadap dosen Teknik Komputer

Menentukan Nilai Vektor (S).

Menentukan Nilai Vektor (S) dapat menggunakan persamaan sebagai berikut;

$$
\mathrm{Si}=\prod_{j=1}^{n} X i j \mathrm{WJ}
$$


JSAI : Journal Scientific and Applied Informatics

Vol. 3, No. 3, November 2020, hal. 175 182

E-ISSN: 2614-3054; P-ISSN: 2614-3062, accredited by Kemenristekdikti, Sinta 5 DOI: 10.36085

$$
\begin{aligned}
& S_{1}=\left(0.2656^{\mathbf{0 . 3 5 2 9}}\right)\left(0.2469^{\mathbf{0 . 2 9 4 1}}\left(0.1938^{\mathbf{0 . 2 3 5 3}}\right)\left(0.2938^{-\mathbf{0 . 1 1 7 6}}\right)=0.3259\right. \\
& S_{2}=\left(0.2531^{\mathbf{0 . 3 5 2 9}}\right)\left(0.2219^{\mathbf{0 . 2 9 4 1}}\left(0.2969^{\mathbf{0 . 2 3 5 3}}\right)\left(0.2281^{-\mathbf{0 . 1 1 7 6}}\right)=0.3536\right. \\
& S_{3}=\left(0.2188^{\mathbf{0 . 3 5 2 9}}\right)\left(0.2219^{\mathbf{0 . 2 9 4 1}}\left(0.1938^{\mathbf{0 . 2 3 5 3}}\right)\left(0.3656^{\mathbf{- 0 . 1 1 7 6}}\right)=0.2874\right. \\
& S_{4}=\left(0.2750^{\mathbf{0 . 3 5 2 9}}\right)\left(0.2563^{\mathbf{0 . 2 9 4 1}}\left(0.2719^{\mathbf{0 . 2 3 5 3}}\right)\left(0.1969^{-\mathbf{0 . 1 1 7 6}}\right)=0.3786\right. \\
& S_{5}=\left(0.2595^{\mathbf{0 . 3 5 2 9}}\right)\left(0.2438^{\mathbf{0 . 2 9 4 1}}\left(0.2938^{\mathbf{0 . 2 3 5 3}}\right)\left(0.2031^{-\mathbf{0 . 1 1 7 6}}\right)=0.3709\right.
\end{aligned}
$$

Menentukan Nilai vector $V$. Dengan menggunakan persamaan berikut ini untuk menghitung preferensi untuk perangkingan;

$$
\begin{gathered}
\mathbf{V i}=\frac{S i}{\prod_{j}^{n}\left(X_{j}^{*}\right) W j} \\
\mathbf{V}_{\mathbf{1}}=\frac{0.3259}{0.3259+0.3536+0.2874+0.3786+0.3709}=\frac{0.3259}{\mathbf{1 . 6 2 6 5}}=\mathbf{0 . 1 8 9 9} \\
\mathbf{V}_{\mathbf{2}}=\frac{0.3536}{0.3259+0.3536+0.2874+0.3786+0.3709}=\frac{0.3536}{\mathbf{1 . 6 2 6 5}}=\mathbf{0 . 2 0 6 0} \\
\mathbf{V}_{\mathbf{3}}=\frac{0.2874}{0.3259+0.3536+0.2874+0.3786+0.3709}=\frac{0.2875}{1.6265}=\mathbf{0 . 1 6 7 4} \\
\mathbf{V}_{\mathbf{4}}=\frac{0.3786}{0.3259+0.3536+0.2874+0.3786+0.3709}=\frac{0.3786}{1.6265}=\mathbf{0 . 2 2 0 6} \\
\mathbf{V}_{\mathbf{5}}=\frac{0.3709}{0.3259+0.3536+0.2874+0.3786+0.3709}=\frac{0.3709}{1.6265}=\mathbf{0 . 2 1 6 1}
\end{gathered}
$$

Nilai preverensi V; V1 $=0.1899, \mathrm{~V} 2=0.2060, \mathrm{V3}=0.1674, \mathrm{~V} 4=0.2206, \mathrm{~V} 5=0.2161$

Tabel 4. Nilai hasil perankingan

\begin{tabular}{cccc}
\hline Rangking & $\begin{array}{c}\text { Nama } \\
\text { dosen/Alternatif }\end{array}$ & Code & Hasil \\
\hline $\mathbf{1}$ & ABUR & A4 & $\mathbf{0 . 2 2 0 6}$ \\
$\mathbf{2}$ & USTH & A5 & $\mathbf{0 . 2 1 6 1}$ \\
$\mathbf{3}$ & INTS & A2 & $\mathbf{0 . 2 0 6 0}$ \\
$\mathbf{4}$ & DSMU & A1 & $\mathbf{0 . 1 8 9 9}$ \\
$\mathbf{5}$ & TNSA & A3 & $\mathbf{0 . 1 6 7 4}$ \\
\hline
\end{tabular}

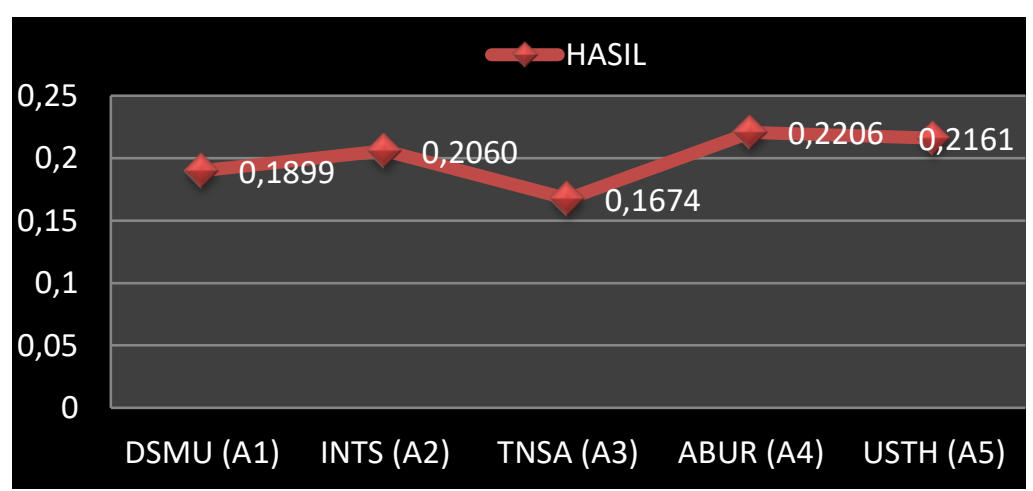

Gambar 2. Grafik hasil analis perhitungan nilai preverensi/vector V 


\section{KESIMPULAN (11 PT)}

A. Penentuan keputusan terbaik dari rekomendasi hasil analisis nilai vector V berdasarkan grafik, maka diperoleh rekomendasi; Dosen terbaik hasil pemilihan yang dilakukan oleh Mahasiswa Teknik Komputer terhadap 5 (lima) Alternatif (dosen) adalah Alternatif (dosen) ABUR $(\mathrm{A} 4)=0.2206$

B. Hasil penelitian ini dilengkapi dengan grafik hasil penankingan sehingga berbeda dengan penelitian sebelumnya yang di jadikan sebagai tinjauan pustakan.

\section{UCAPAN TERIMA KASIH}

Kepada Direktur Akademi Ilmu Komputer Ternate yang telah memberika kesempatan kepada peneliti untuk melaksanakan penelitian pada Akademi Ilmu Komputer Ternate. Kepada Ketua Prodi Teknik Komputer, Ketua Penjaminan mutu, dan Pembatu Direktur I bidang akademik yang bersedia di wawancara untuk pengambilan data penelitian. Kepada rekan-rekan dosen dan mahasiswa Akademi Ilmu Komputer Ternate yang selalu meluangkan waktu untuk berdiskusi terkait dengan penelitian. Kepada Pengelola Jurnal JSAI : Journal Scientific and Applied Informatics yang menerima dan bersedia untuk mempublis hasil penelitian ini.

\section{REFERENSI}

[1] Sujaini, Herry, and Helen Sasty Pratiwi. 2016. "DOSEN TERBAIK MENGGUNAKAN METODE PROMETHEE ( STUDI KASUS : TEKNIK INFORMATIKA UNIVERSITAS TANJUNGPURA )." 1(1):1-6.

[2] Rini, Puput Puspito, Dedi, and Nova Riyanti. 2015. "Sistem Pendukung Keputusan Pemilihan Dosen Terbaik Berbasis Web Dengan Metode SAW (Simple Additive Weighting) (Studi Kasus: STMIK Global Tangerang)." Sisfotek Global 5(2):9.

[3] Widagdo, Putut Pamilih, Ramadiani, Septya Maharani, and Eko Junirianto. 2019. "Sistem Informasi Akreditasi Program Studi Di Fakultas Ilmu Komputer Dan Teknolgi Informasi Universitas Mulawarman.” Query: Jurnal Sistem Informasi 3(2):14.

[4] Sulastri, C., Siswanti, S., \& KW, A. K. 2016. "Sistem Pendukung Keputusan Penilaian Dosen Berprestasi Menggunakan Weighted Product (Wp) Di Stikes Alma Ata Yogyakarta." Jurnal Teknologi Informasi Dan Komunikasi 4(2):62-68.

[5] Marpaung, Nasrun, Masitah Handayani, and Rolly Yesputra. 2018. "Sistem Pendukung Keputusan Pemilihan Dosen Terbaik Dengan Metode Weighted Product (WP) Pada STMIK Royal.” Seminar Nasional Royal 2018 9986(September):267-70.

[6] Hidayat, Cepi Rahmat, Teuku Mufizar, and Muhamad Dadan Ramdani. 2018. "Implementasi Metode Weighted Product ( Wp ) Pada Sistem Pendukung Keputusan Seleksi Calon Karyawan Bpjs Kesehatan Tasikmalaya." 8-9.

[7] Ishak, Rezqiwati. 2016. "Jurnal Ilmiah ILKOM Volume 8 Nomor 3 ( Desember 2016 ) SISTEM PENDUKUNG KEPUTUSAN PEMILIHAN PENYULUH LAPANGAN KELUARGA Copyright ( 2016 -- Jurnal Ilmiah ILKOM -- All Rights Reserved . Jurnal Ilmiah ILKOM Volume 8 Nomor 3 ( Desember 2016 )." 8(Desember):160-66.

[8] Kusrini. 2007. Konsep dan Aplikasi Sistem Pendukung Keputusan. Yogyakarta: C.V Andi Offet.

[9] Khairina, Dyna Marisa, Dio Ivando, and Septya Maharani. 2016. "Implementasi Metode Weighted Product Untuk Aplikasi Pemilihan Smartphone Android." 8(1):1-8.

[10] Syafitri, Nur Arifah, Anita Puspita Dewi. 2016. Penerapan Metode Weighted Product dalam Sistem Pendukung Keputusan Pemilihan Laptop Berbasis Web Jurusan Teknik Informatika, 2(1) : 169-176

[11] Linden, Isabelle, Shaofeng Liu, Fátima Dargam, Jorge E. Hernández, Euro Working, and Group Conferences. 2014. Decision Support Systems IV - Information and Knowledge.

[12] Prasetyo, Budi, Timothy John Pattiasina, and Anggya Nanda Soetarmono. 2015. "Perancangan Dan Pembuatan Sistem Informasi Gudang (Studi Kasus : PT. PLN (Persero) Area Surabaya Barat)." Teknika 4(1):12-16.

[13] Yasdomi, Kiki, and Urfi Utami. 2018. "Sistem Pendukung Keputusan Karyawan Terbaik Menggunakan Metode Weight Product ( WP ) ( Studi Kasus : Universitas Pasir Pengaraian )." 
JSAI : Journal Scientific and Applied Informatics

Vol. 3, No. 3, November 2020, hal. 175 182

E-ISSN: 2614-3054; P-ISSN: 2614-3062, accredited by Kemenristekdikti, Sinta 5

DOI: 10.36085

4(1):129-43.

[14] Sulastri, C., Siswanti, S., \& KW, A. K. 2016. "Sistem Pendukung Keputusan Penilaian Dosen Berprestasi Menggunakan Weighted Product (Wp) Di Stikes Alma Ata Yogyakarta." Jurnal Teknologi Informasi Dan Komunikasi 4(2):62-68.

[15] Marpaung, Nasrun, Masitah Handayani, and Rolly Yesputra. 2018. "Sistem Pendukung Keputusan Pemilihan Dosen Terbaik Dengan Metode Weighted Product (WP) Pada STMIK Royal.” Seminar Nasional Royal 2018 9986(September):267-70. 